\title{
Genome-Wide Prediction of Potential Vaccine Candidates for Campylobacter jejuni Using Reverse Vaccinology
}

\author{
Richa Jain $^{1,5} \cdot$ Sarita Singh $^{2} \cdot$ Santosh kumar Verma ${ }^{3} \cdot$ Ankit Jain $^{4}$
}

Received: 30 May 2017 / Revised: 1 August 2017 / Accepted: 1 September 2017 / Published online: 11 November 2017

(C) Springer-Verlag GmbH Germany 2017

\begin{abstract}
Campylobacteriosis is a deadly disease which has developed resistance to most of the available chemotherapeutic agents. Although various studies provide evidence of acquired immunity following exposure to Campylobacter jejuni, no effective vaccine has been developed, still. Hence, there is an urgent need to identify potential vaccine candidates for Campylobacter species. In the proposed study, Campylobacter jejuni subsp. jejuni serotype O:2 (strain NCTC 11168) was taken and computational approach was employed to screen $C$. jejuni genome for promising vaccine candidates. From 1623 protein-coding sequences, 37 potential antigens were screened for epitope prediction based on surface association, consensus antigenicity predictions, solubility, transmembrane domain, and ortholog analysis. Comprehensive immunogenic analysis of these 37 antigens revealed that antigen Q0PA22 shows the greatest potential for experimental immunogenicity analysis. It has several potential CD4+ and CD8+ T-cell epitopes, as well as high probability of B-cell epitope regions as compared to well-characterized antigen
\end{abstract}

Electronic supplementary material The online version of this article (doi:10.1007/s12539-017-0260-5) contains supplementary material, which is available to authorized users.

\section{Richa Jain}

richa.jain917@gmail.com

1 Institute of Engineering and Technology, Sitapur Road, Lucknow, India

2 Biotech Park, Lucknow, India

3 Department of Environmental science and engineering, ISM dhanbad, Dhanbad 826004, India

4 India Meteorological Department, New Delhi 110003, India

5 Meteorological Office, Surmane IVRI campus, Mukteshwar, Nanital 263138, India
Omp18 (Uniprot ID:Q0PC24). Among the highest scoring predicted epitopes, an optimal set of epitopes with respect to overall immunogenicity in target populations for campylobacteriosis viz. Europe, North America and Southwest Asia was determined. An epitope AMLTYMQWL from antigen no. 6(Q0PA22) binds to the most prevalent allele HLA-A*0201, and this epitope has most immunogenicity for all the target populations. In addition, this epitope exhibited highly significant TCR-pMHC interactions having a joint $Z$ value of 4.87. Homology mapping studies of the predicted epitope show best homology to a well-studied antigenic peptide from influenza virus $\mathrm{H} 5 \mathrm{~N} 1$. Therefore, the predicted epitope might be a suitable vaccine candidate.

Keywords Campylobacter $\cdot$ Reverse vaccinology . MHC $\cdot$ Epitope $\cdot$ Vaccine

\section{Introduction}

Campylobacteriosis is a collective description for infectious diseases caused by members of the bacterial genus Campylobacter, found in animals such as poultry, cattle, pigs, wild birds, and wild mammals. Campylobacteriosis constitutes serious medical and socioeconomic problem worldwide. Campylobacter bacterium is one of the major causes of foodborne diarrhoeal illness in humans, and in addition, it is the most common bacterium that causes gastroenteritis worldwide. Some virulence factors have been identified in campylobacter including flagella-mediated motility, bacterial adherence to intestinal mucosa, invasive capability, and the ability to produce toxins. [1-3]. The disease campylobacteriosis is associated with numerous sequelae, including Guillain-Barré Syndrome, inflammatory bowel disease, 
reactive arthritis, and irritable bowel syndrome. Guillain-Barré syndrome is a rapidly progressive acute flaccid paralysis that results from inflammatory demyelination of peripheral nerves and is the most severe and life-threatening postinfectious sequelae of campylobacteriosis [4]. Other intestinal complications include intestinal hemorrhage, perforation, ulceration, abscesses, and toxic megacolon [5]. Extra intestinal complications include meningitis, endocarditis, hepatitis, cholecystitis, osteomyelitis, pancreatitis, splenic rupture, and septic abortion [6].

At present, there are 17 species and 6 subspecies assigned to the genus Campylobacter. Among Campylobacter species, C. jejuni accounts for more than $92 \%$ of human infections [7, 8]. 1.3 million people are affected and approximately 76 people with Campylobacter infections die each year [9]. Chemotherapeutics are available for campylobacteriosis, but studies show that bacteria have developed resistance against most of them. Mainly, three mechanisms appear to be involved in antibiotic resistance in C. jejuni, namely, efflux of the antibiotic, mutation of the target site, and protection of the target site azithromycin and fluoroquinolones (e.g., ciprofloxacin, quinolone, ofloxacin, levofloxacin, and norfloxacin) are commonly used for treatment of these infections, but resistance to fluoroquinolones is common [9].

Circulating anti-campylobacter antibodies obtained by the experimental evidence suggests that, in humans, every primary exposure can generate an immune response and secondary exposures can enhance and contribute to that response [10]. It has been well established that prior infection with $C$. jejuni can induce protective immunity against Campylobacter infections in humans and animals; this strongly supports the feasibility of development of immunization-based approaches to control Campylobacter infections [11]. The epidemiological and experimental studies provide evidence of acquired immunity following exposure to $C$. jejuni, lending support for vaccine development [12]. Any approved vaccine for Campylobacter is not available until now; therefore, it is necessary to develop effective vaccines.

'Reverse vaccinology' is a recent approach, which starts from the genomic sequence and, by computer analysis, predicts those antigens that are most likely to be vaccine candidates [13]. Vaccine development by reverse vaccinology involves the in silico analysis of microbial genome sequences followed by the high-throughput expression of the genes of interest. Then, the recombinant proteins are used to immunize mice. The ability of the polypeptide to elicit a quantitative and qualitative immune response is assessed by analysing the post-immunization sera. This concept was first successfully applied for development of a vaccine against serogroup B Neisseria minigitidis (MenB). It took less than 18 months to identify more and some novel vaccine candidates in MenB than had been discovered during the past 40 years by the conventional methods [14] and a vaccine (Bexsero ${ }^{\circledR}$ ) including 3 novel antigens and outer membrane vesicles is now licensed in 30 countries [15]. Reverse vaccinology is now being applied to many bacterial, viral, and eukaryotic pathogens and has been successful in all cases in providing novel antigens for the design of new vaccines [16]. Some applications of reverse vaccinology include Streptococcus pneumoniae, Porphyromonas gingivalis, Chlamydia pneumoniae, Bacillus anthracis, Streptococcus agalactiae, Streptococcus pyogenes, Plasmodium spp., enteropathogenic Escherichia coli (EPEC) and many others [17].

In the present study, $C$. jejuni subsp. jejuni serotype $\mathrm{O}: 2$ (strain NCTC 11168) which is known as major cause of campylobacteriosis was undertaken to characterize its antigens as potential vaccine candidates.

\section{Materials and Methods}

\subsection{Retrieval of Proteome data sets}

Complete sequenced proteome of $C$. jejuni subsp. jejuni serotype O:2 (strain NCTC 11168) consisting of 1623 protein-coding sequences has been retrieved from Uniprot database (http://www.uniprot.org/). A well-characterized, immuno-dominant antigen 'omp18' (Uniprot id Q0PC24) was also included as control to compare and validate the outcome of study. This known antigen had previously tested and verified in various experimental studies and was reported as capable of eliciting high immune response [18].

\subsection{Vaccine Candidate Characterization and Epitope Prediction}

Genome-wide characterization of the potential vaccine candidates has been carried out using various computational tools as described below. Initially, the $C$. jejuni proteome has been screened for surface-associated proteins with the use of SignalP and SecretomeP tools. SignalP server predicts the presence and location of signal peptide cleavage sites in amino acid sequences from different organisms. It is a purely neural network-based method [19]. The SecretomeP 2.0 server produces ab initio predictions of non-classical, i.e., not signal peptide triggered protein secretion. It is also based on artificial neural networks [20]. Then, consensus antigenicity predictions have been carried out using Vaxijen and ANTIGENpro 
servers. Vaxijen tool was developed for antigen classification solely based on the physiochemical properties of proteins without recourse to sequence alignment [21], and ANTIGENpro is a sequence-based, alignment-free and pathogen-independent predictor of protein antigenicity [22]. Finally, selected antigens have been further characterized based on solubility predictions using ESPRESSO, a sequence-based predictor for estimating protein expression and solubility [23], transmembrane domain predictions using TMHMM server based on a hidden Markov model [24], and BLAST for ortholog analysis [25].

\subsubsection{Epitope Prediction}

B-cell epitope prediction has been carried out using IEDB B-cell epitope prediction tools. A collection of methods to predict continuous linear B-cell epitopes and amino acid scales, are available at IEDB http://tools.immuneepitope. org/bcell. These tools predict regions of proteins that are likely to be recognized as epitopes in the context of a B-cell response. Furthermore, CTL epitope prediction has been carried out using NetCTL tool. It is artificial neural network-based tool and does so by integrating predictions of peptide MHC class I binding, proteasomal C terminal cleavage, and TAP transport efficiency. NetCTL provides a comprehensive prediction about epitopes binding to 12 HLA class I supertypes including 5 HLA-A [A1, A2, A3, A24, A26] and 7 HLA-B [B7, B8, B27, B39, B44, B58, B62] [26]. To predict binding of peptides to HLA-DR, HLA-DQ, HLA-DP, and mouse MHC class II alleles, NetMHCII 2.2 server has been used. It is based on artificial neural networks [27].

\subsubsection{Population Coverage Analysis and pMHC-TCR Interaction Analysis}

Optitope tool has been used to determine the optimal set of epitopes from among the predicted epitopes, which will yield the best immune response in the target populations/geographic areas for the campylobacteriosis viz. Europe, North America and Southwest Asia. OptiTope deployed three widely used MHC class I binding affinity prediction methods, namely, BIMAS, SYFPEITHI and SVMHC [28].

Furthermore, the PAComplex server has been employed to predict TCR-pMHC interactions of a target protein or a set of peptides and search template-based homologous peptide antigens for the query protein sequence. This server first identifies significantly similar TCR-pMHC templates (joint
$Z$ value $\geq 4.0$ ) of the query using antibody-antigen and protein-protein interacting scoring matrices for peptide-TCR and pMHC interfaces, respectively [29]. The joint $Z$ value $\left(J_{z}\right)$ is defined as

$J_{z}=\sqrt{Z_{\mathrm{MHC}} \times Z_{\mathrm{TCR}}}$

[30]. Here, $J_{z} \geq 4.0$ is considered a significant similarity according to the statistical analysis.

PAComplex then identifies the homologous peptide antigens of these hit templates from complete pathogen genome databases and experimental peptide databases. Finally, the server outputs peptide antigens and homologous peptide antigens of the query and displays detailed interacting models of hit TCR-pMHC templates. Here, the CTL epitope set predicted by NetCTL and optimized by Optitope for the different target populations has been used as the target peptide set and TCR-pMHC interactions have been analyzed.

\subsubsection{Epitope Homology Mapping}

The IEDB homology mapping tool maps linear epitopes to 3D structures of proteins [31]. This is done by comparing the epitope source protein sequence with that of proteins with known 3D structures in the PDB. The tool generates an alignment between the target sequence of the epitope source sequence and a homologous sequence from the PDB, and visualizes the result in an Epitope Viewer.

\section{Results and Discussion}

Campylobacter jejuni infection is commonly self-limiting, but persistent disease can occur, and in addition, a number of chronic sequelae have been identified. The fact that recovery from a primary infection renders the host resistant to subsequent infections indicates that a vaccine against Campylobacter is feasible. In this study, genome-wide screening was done using various computational tools that provide an in hand idea to predict and design new vaccine and vaccine components.

\subsection{Selection of Antigens and Their Characterization}

The entire protein repertoire of C. jejuni, consisting of 1623 protein-coding sequences, has been screened for proteins with signal peptides, which account for secretion of protein through classical pathway as well as for proteins which secrete through non-classical pathway. Out of these 1623, 113 proteins have been found to contain signal peptides, using SignalP tool (Table S1) and 143 proteins have been 
found to be secreted through non-classical pathway in the cell, using SecretomeP tool (Table S2). Thus, total 256 secretory proteins have been selected.

Further screening involves antigenicity predictions of these 256 proteins using VaxiJen and ANTIGENpro tools. Predefined threshold of 0.6 has been applied for both the tools as this value provide results with better accuracy, sensitivity, and specificity [21, 22]. In this analysis, 60 proteins have shown antigenic probability $\geq 0.6$; therefore, based on the consensus predictions, these 60 antigenic proteins have been taken for further analysis (Table 1). Control antigen Omp18 (Uniprot Id Q0PC24) has been predicted as nonclassically secreted protein using SecretomeP tool. It has been found to be antigenic by both VaxiJen and ANTIGENpro tools.

Protein insolubility has been known to be a major obstacle for many experimental studies; thus, 60 antigenic proteins predicted in the previous step have been subjected to predict the propensity of a protein to be soluble on overexpression using ESPRESSO tool. Out of the 60 antigenic proteins, 45 have been predicted to be soluble on overexpression and control antigen Omp18 has been predicted to be soluble on overexpression (Table S3). In transmembrane domain prediction of these 60 proteins using TMHMM server, only 1 antigen has been predicted to contain two transmembrane regions, 8 antigens (nos. 11, 18, 21, 32, 38, 43, 47, 51 in Table S3) with one, while rest antigens have been found to contain no TM regions (Table S3). The control antigen Omp18 has also not shown any TM regions. An issue in vaccine development is the possibility that vaccine candidates showing sequence identity with the host (e.g., human or mouse) proteins are likely to cause autoimmunity in the host, and thus should be discarded to avoid potential autoimmunity. In this study, potential orthologs in the human and mouse host have been searched using reciprocal BLASTP. Out of the selected 45, 8 antigens (nos. 13, 24, 27, 30, 36, 40, 43, 50 in Table S3) show orthologs in human and mouse. These may be predicted to have the potential of generating autoimmune response and, thus, are discarded for the further analysis. Based on screening so far, finally, 37 candidate antigens have been selected for epitope prediction (Table 2).

\subsection{Epitope-based analysis of the selected antigens}

A high probability of B-cell epitope regions has been observed in eight antigens (nos. 3, 6, 11, 12, 24, 26, 31, and 37 in Table 2) using linear B-cell epitope prediction methods. Among these, antigen no. 6 (Q0PA22) has been found to show the highest probability in the region ranging from 65 to 80 and 150 to 165 , as shown in Fig. 1a-f (in each graph, the yellow area above the threshold depicts the region of high propensity of the particular physico-chemical property to which the method corresponds). These regions have been
Table 1 List of proteins predicted to be antigenic with corresponding antigenic probabilities

\begin{tabular}{|c|c|c|c|}
\hline \multirow[t]{2}{*}{ Protein no. } & \multirow[t]{2}{*}{ Uniprot id } & \multicolumn{2}{|c|}{ Antigenic Probability } \\
\hline & & VaxiJen & ANTIGENpro \\
\hline 1 & Q0P9Q4 & 0.6028 & NA \\
\hline $2 *$ & Q0P8E9 & 0.6043 & 0.948972 \\
\hline 3 & Q9PIQ1 & 0.6057 & NA \\
\hline $4 *$ & Q0P7V9 & 0.609 & 0.750863 \\
\hline $5^{*}$ & Q0PBX9 & 0.6092 & 0.864711 \\
\hline 6 & Q0PBW0 & 0.6096 & NA \\
\hline 7 & Q0P9Z0 & 0.6104 & NA \\
\hline $8^{*}$ & Q0P901 & 0.6104 & 0.722062 \\
\hline $9 *$ & P80672 & 0.6142 & 0.722752 \\
\hline $10^{*}$ & Q0PC85 & 0.6142 & 0.828451 \\
\hline $11^{*}$ & Q0PBR9 & 0.6152 & 0.612435 \\
\hline $12^{*}$ & Q0PAI1 & 0.6177 & 0.907918 \\
\hline 13 & Q0P7Q8 & 0.6209 & NA \\
\hline $14^{*}$ & Q0PA21 & 0.625 & 0.641823 \\
\hline $15^{*}$ & Q0PBH3 & 0.6358 & 0.934759 \\
\hline $16^{*}$ & Q0PAD8 & 0.6378 & 0.872639 \\
\hline $17 *$ & Q9PIR0 & 0.6394 & 0.949683 \\
\hline $18^{*}$ & O69302 & 0.6403 & 0.888151 \\
\hline 19 & Q0PBD5 & 0.6475 & NA \\
\hline 20 & Q0PBW3 & 0.6475 & NA \\
\hline $21^{*}$ & Q9PLX1 & 0.6476 & 0.862718 \\
\hline $22^{*}$ & Q0P8Y7 & 0.6484 & 0.605215 \\
\hline $23 *$ & Q46125 & 0.6502 & 0.705779 \\
\hline $24^{*}$ & Q0P7X0 & 0.6505 & 0.843714 \\
\hline $25^{*}$ & Q0P8M7 & 0.6505 & 0.861401 \\
\hline $26^{*}$ & Q0P986 & 0.6514 & 0.666757 \\
\hline 27 & P45492 & 0.6514 & NA \\
\hline $28^{*}$ & Q0P8M8 & 0.655 & 0.66418 \\
\hline 29 & Q0PA70 & 0.6555 & NA \\
\hline $30^{*}$ & Q0PC83 & 0.6572 & 0.94006 \\
\hline 31 & Q0P937 & 0.66 & NA \\
\hline $32 *$ & Q0PBB9 & 0.6606 & 0.945148 \\
\hline 33 & Q0PBV8 & 0.6633 & NA \\
\hline $34^{*}$ & Q9PI18 & 0.6641 & 0.68324 \\
\hline $35^{*}$ & Q9PLX6 & 0.6725 & 0.809367 \\
\hline $36^{*}$ & Q0PA22 & 0.6772 & 0.609157 \\
\hline $37 *$ & O85213 & 0.6783 & 0.837565 \\
\hline $38^{*}$ & Q0PC23 & 0.6809 & 0.910274 \\
\hline $39 *$ & Q0P7X2 & 0.6842 & 0.821075 \\
\hline 40 & Q0PAE1 & 0.6852 & NA \\
\hline $41^{*}$ & Q9PLX4 & 0.6856 & 0.704542 \\
\hline $42^{*}$ & Q0P8M0 & 0.6876 & 0.695071 \\
\hline $43^{*}$ & Q0P8Q1 & 0.6954 & 0.957489 \\
\hline $44 *$ & Q0P9S7 & 0.6956 & 0.857222 \\
\hline $45^{*}$ & Q9PPM0 & 0.6974 & 0.934889 \\
\hline $46^{*}$ & Q0PA11 & 0.6976 & 0.95496 \\
\hline 47 & Q9PIP2 & 0.6985 & NA \\
\hline
\end{tabular}


Table 1 (continued)

\begin{tabular}{|c|c|c|c|}
\hline \multirow[t]{2}{*}{ Protein no. } & \multirow[t]{2}{*}{ Uniprot id } & \multicolumn{2}{|c|}{ Antigenic Probability } \\
\hline & & VaxiJen & ANTIGENpro \\
\hline $48^{*}$ & Q0P7V2 & 0.7041 & 0.942272 \\
\hline $49 *$ & Q0P8X7 & 0.7054 & 0.844563 \\
\hline $50 *$ & Q9PHW6 & 0.7146 & 0.938164 \\
\hline $51 *$ & Q0PAR1 & 0.7168 & 0.92021 \\
\hline $52 *$ & P56964 & 0.7211 & 0.926111 \\
\hline 53 & Q9PLY2 & 0.7212 & NA \\
\hline 54 & Q0P9W3 & 0.7357 & NA \\
\hline $55^{*}$ & Q9PMI3 & 0.736 & 0.681929 \\
\hline 56 & Q0PB93 & 0.7372 & NA \\
\hline $57 *$ & Q0PAN9 & 0.7387 & 0.949942 \\
\hline $58 *$ & Q0P7Z7 & 0.7397 & 0.831528 \\
\hline $59 *$ & Q0PBN7 & 0.7458 & 0.914245 \\
\hline $60 *$ & Q0P7T9 & 0.7475 & 0.683849 \\
\hline $61 *$ & P56963 & 0.7571 & 0.915357 \\
\hline $62 *$ & Q0PC44 & 0.7782 & 0.884757 \\
\hline $63 *$ & Q0P7X5 & 0.7783 & 0.681143 \\
\hline $64 *$ & Q9PMJ8 & 0.7886 & 0.843072 \\
\hline $65^{*}$ & Q0P7Q2 & 0.7888 & 0.939832 \\
\hline 66 & Q0PAE0 & 0.79 & NA \\
\hline $67 *$ & Q0PAS3 & 0.7902 & 0.63537 \\
\hline $68^{*}$ & Q0PBA6 & 0.7931 & 0.95115 \\
\hline 69 & Q0P7U2 & 0.7958 & NA \\
\hline $70 *$ & Q0P9T0 & 0.7993 & 0.907989 \\
\hline $71 *$ & Q0PAS5 & 0.8014 & 0.899646 \\
\hline $72 *$ & Q9PI58 & 0.8297 & 0.67936 \\
\hline $73 *$ & Q0PB90 & 0.8359 & 0.636843 \\
\hline $74 *$ & Q0P914 & 0.8535 & 0.741765 \\
\hline 75 & Q0P8F1 & 0.8564 & NA \\
\hline $76^{*}$ & Q0PB82 & 0.8586 & 0.659147 \\
\hline 77 & Q0P9N1 & 0.8672 & NA \\
\hline 78 & Q0PBX0 & 0.8707 & NA \\
\hline 79 & Q9PIX2 & 0.8766 & NA \\
\hline $80 *$ & Q0PAW9 & 0.8807 & 0.919957 \\
\hline 81 & Q9PIG9 & 0.8818 & NA \\
\hline 82 & Q0PA72 & 0.8957 & NA \\
\hline 83 & Q0P8R1 & 0.9025 & NA \\
\hline 84 & Q0PA31 & 0.9818 & NA \\
\hline $85^{*}$ & Q0PB92 & 1.0362 & 0.884229 \\
\hline $86^{*}$ & Q0PC84 & 1.0657 & 0.967576 \\
\hline 87 & Q9PNX4 & 1.0733 & NA \\
\hline 88 & Q9PI38 & 1.1964 & NA \\
\hline 89 & Q9PHM1 & NA & 0.961057 \\
\hline 90 & Q0PA96 & NA & 0.952036 \\
\hline 91 & Q0P8G5 & NA & 0.942712 \\
\hline 92 & Q9PID1 & NA & 0.938776 \\
\hline 93 & P96747 & NA & 0.931745 \\
\hline 94 & Q0P9T3 & NA & 0.92947 \\
\hline 95 & Q0PAA7 & NA & 0.929047 \\
\hline
\end{tabular}

Table 1 (continued)

\begin{tabular}{|c|c|c|c|}
\hline \multirow[t]{2}{*}{ Protein no. } & \multirow[t]{2}{*}{ Uniprot id } & \multicolumn{2}{|c|}{ Antigenic Probability } \\
\hline & & VaxiJen & ANTIGENpro \\
\hline$\overline{96}$ & Q0PC45 & NA & 0.928969 \\
\hline 97 & Q0PBA4 & NA & 0.921329 \\
\hline 98 & Q0P8Q2 & NA & 0.916345 \\
\hline 99 & Q0PA76 & NA & 0.913673 \\
\hline 100 & Q0PAI2 & NA & 0.913256 \\
\hline 101 & Q0PAH9 & NA & 0.911741 \\
\hline 102 & Q0PBW9 & NA & 0.906708 \\
\hline 103 & Q0PAY8 & NA & 0.906706 \\
\hline 104 & Q0PAE2 & NA & 0.9005 \\
\hline 105 & Q0PC46 & NA & 0.896823 \\
\hline 106 & Q0PAD4 & NA & 0.892556 \\
\hline 107 & Q0PB95 & NA & 0.879982 \\
\hline 108 & Q0PAV7 & NA & 0.876737 \\
\hline 109 & Q0P9T1 & NA & 0.876657 \\
\hline 110 & Q0P967 & NA & 0.875618 \\
\hline 111 & Q0P9M6 & NA & 0.868266 \\
\hline 112 & Q0PBW1 & NA & 0.865464 \\
\hline 113 & Q0PCC0 & NA & 0.864433 \\
\hline 114 & Q9PHY8 & NA & 0.860455 \\
\hline 115 & Q0P802 & NA & 0.857528 \\
\hline 116 & Q0PA41 & NA & 0.845508 \\
\hline 117 & Q0P970 & NA & 0.844061 \\
\hline 118 & Q0PC26 & NA & 0.841645 \\
\hline 119 & Q0PCA5 & NA & 0.84138 \\
\hline 120 & Q0PAB4 & NA & 0.840881 \\
\hline 121 & Q0PB96 & NA & 0.83628 \\
\hline 122 & Q0P7Z8 & NA & 0.82534 \\
\hline 123 & Q0P941 & NA & 0.824701 \\
\hline 124 & Q0PBH6 & NA & 0.823866 \\
\hline 125 & Q0PAY9 & NA & 0.82338 \\
\hline 126 & Q0PBZ2 & NA & 0.816098 \\
\hline 127 & Q0P8W8 & NA & 0.810707 \\
\hline 128 & Q9PI35 & NA & 0.809116 \\
\hline 129 & Q0P8C8 & NA & 0.795077 \\
\hline 130 & Q9PM82 & NA & 0.790075 \\
\hline 131 & Q0PC89 & NA & 0.789636 \\
\hline 132 & Q9PLX2 & NA & 0.787269 \\
\hline 133 & Q0PAS1 & NA & 0.784577 \\
\hline 134 & Q0P928 & NA & 0.783668 \\
\hline 135 & Q0PBR2 & NA & 0.781652 \\
\hline 136 & Q0PBE5 & NA & 0.781205 \\
\hline 137 & Q0P814 & NA & 0.780918 \\
\hline 138 & Q0P8P4 & NA & 0.779281 \\
\hline 139 & Q0PC56 & NA & 0.777948 \\
\hline 140 & Q0PBE3 & NA & 0.772361 \\
\hline 141 & Q0PBL7 & NA & 0.770826 \\
\hline 142 & Q0PAU9 & NA & 0.770272 \\
\hline 143 & Q0PAE3 & NA & 0.768064 \\
\hline
\end{tabular}


Table 1 (continued)

\begin{tabular}{|c|c|c|c|}
\hline \multirow[t]{2}{*}{ Protein no. } & \multirow[t]{2}{*}{ Uniprot id } & \multicolumn{2}{|c|}{ Antigenic Probability } \\
\hline & & VaxiJen & ANTIGENpro \\
\hline$\overline{144}$ & Q0PAQ4 & NA & 0.759686 \\
\hline 145 & Q9PI34 & NA & 0.757501 \\
\hline 146 & Q0P963 & NA & 0.757383 \\
\hline 147 & Q0PBP1 & NA & 0.75392 \\
\hline 148 & Q9PJ14 & NA & 0.753903 \\
\hline 149 & Q0PC77 & NA & 0.753814 \\
\hline 150 & Q0P8F9 & NA & 0.751982 \\
\hline 151 & Q0P8H0 & NA & 0.750958 \\
\hline 152 & Q0PAX6 & NA & 0.74712 \\
\hline 153 & Q0P9N4 & NA & 0.746667 \\
\hline 154 & Q0P956 & NA & 0.744434 \\
\hline 155 & Q0PA75 & NA & 0.742188 \\
\hline 156 & Q0PAE4 & NA & 0.7407 \\
\hline 157 & Q0PC57 & NA & 0.730971 \\
\hline 158 & Q0P9F8 & NA & 0.728406 \\
\hline 159 & Q0P7W1 & NA & 0.719936 \\
\hline 160 & Q0PBY5 & NA & 0.715185 \\
\hline 161 & Q0PBT9 & NA & 0.707932 \\
\hline 162 & Q0PB86 & NA & 0.692799 \\
\hline 163 & Q0PBF1 & NA & 0.688843 \\
\hline 164 & Q0PBT7 & NA & 0.68668 \\
\hline 165 & Q0PB85 & NA & 0.685236 \\
\hline 166 & Q9PNB9 & NA & 0.685118 \\
\hline 167 & Q9PLX5 & NA & 0.680692 \\
\hline 168 & Q0PA26 & NA & 0.680242 \\
\hline 169 & Q0P8M9 & NA & 0.669246 \\
\hline 170 & Q0PAG4 & NA & 0.668708 \\
\hline 171 & Q9PIC3 & NA & 0.665268 \\
\hline 172 & Q0P987 & NA & 0.661024 \\
\hline 173 & Q0P904 & NA & 0.659951 \\
\hline 174 & Q0PBZ4 & NA & 0.656962 \\
\hline 175 & Q0PA74 & NA & 0.644487 \\
\hline 176 & Q0PAF1 & NA & 0.626031 \\
\hline 178 & Q0P885 & NA & 0.62296 \\
\hline 179 & Q0P7S6 & NA & 0.621245 \\
\hline 180 & Q0PAF2 & NA & 0.62011 \\
\hline 181 & Q0PAI5 & NA & 0.619895 \\
\hline 182 & Q46121 & NA & 0.60753 \\
\hline Omp18 & Q0PC24 & 0.96 & 0.931913 \\
\hline
\end{tabular}

*Proteins which are common in both VaxiJen and ANTIGENpro tools

predicted to elicit significant humoral immune response, thus, the probable region for B-cell epitope.

T-cell epitope predictions have also been performed for the selected 37 antigens using NetCTL and NetMHC II program. For HLA class I supertypes, based on the highest
Table 2 List of selected 37 candidate antigens

\begin{tabular}{|c|c|c|}
\hline & 1 & Q0P8E9 \\
\hline & 2 & Q0PBX9 \\
\hline & 3 & Q0P901 \\
\hline & 4 & Q0PC85 \\
\hline & 5 & Q0PBR9 \\
\hline & 6 & Q0PA22 \\
\hline & 7 & Q0PBH3 \\
\hline & 8 & Q0PAD8 \\
\hline & 9 & O69302 \\
\hline & 10 & Q9PLX1 \\
\hline & 11 & Q0P8Y7 \\
\hline & 12 & Q46125 \\
\hline & 13 & Q0PC83 \\
\hline & 14 & Q0PBB9 \\
\hline & 15 & Q9PLX6 \\
\hline & 16 & Q0PA21 \\
\hline & 17 & Q0PC23 \\
\hline & 18 & Q0P8M0 \\
\hline & 19 & Q0P8Q1 \\
\hline & 20 & Q9PPM0 \\
\hline & 21 & Q9PHW6 \\
\hline & 22 & Q0PAR1 \\
\hline & 23 & Q0P7Z7 \\
\hline & 24 & Q0P7T9 \\
\hline & 25 & Q0PC44 \\
\hline & 26 & Q0P7X5 \\
\hline & 27 & Q9PMJ8 \\
\hline & 28 & Q0PBA6 \\
\hline & 29 & Q0P9T0 \\
\hline & 30 & Q0PAS5 \\
\hline & 31 & Q9PI58 \\
\hline & 32 & Q0PB90 \\
\hline & 33 & Q0P914 \\
\hline & 34 & Q0PB82 \\
\hline & 35 & Q0PAW9 \\
\hline & 36 & Q0PC84 \\
\hline & 37 & Q0PB92 \\
\hline & Omp18 & Q0PC24 \\
\hline
\end{tabular}

value of combined score obtained using NetCTL, a total of 2512 putative CTL epitopes have been predicted, including 1217 HLA-A (247 A1, 245 A2, 328 A3, 156 A24, 241 A26) (Table S4a) and 1295 HLA-B (123-B7, 170-B8, 128B27, 189-B39, 131-B44, 153-B58, 401-B62) (Table S4b) supertype binding peptides. Antigen no. 6 has been found to show greater number of potential CD4 + and CD $8+\mathrm{T}$-cell epitopes, as compared to well-characterized antigen Omp18 


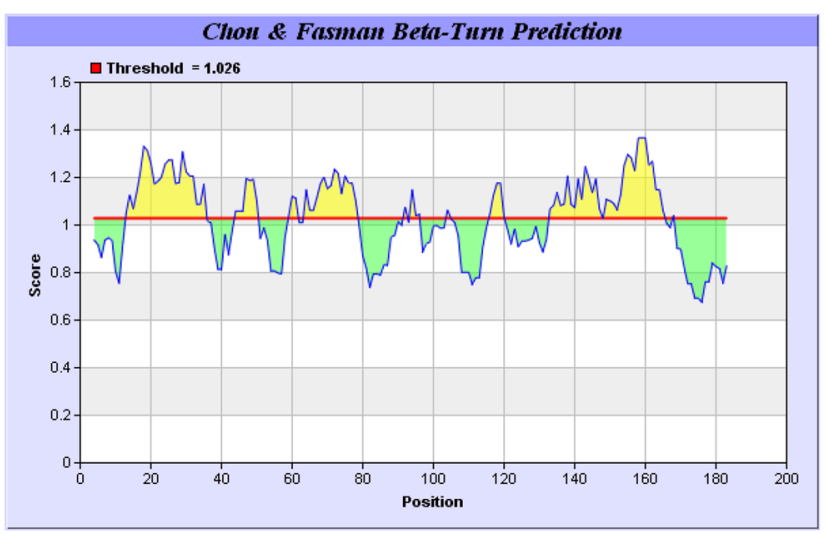

(a)

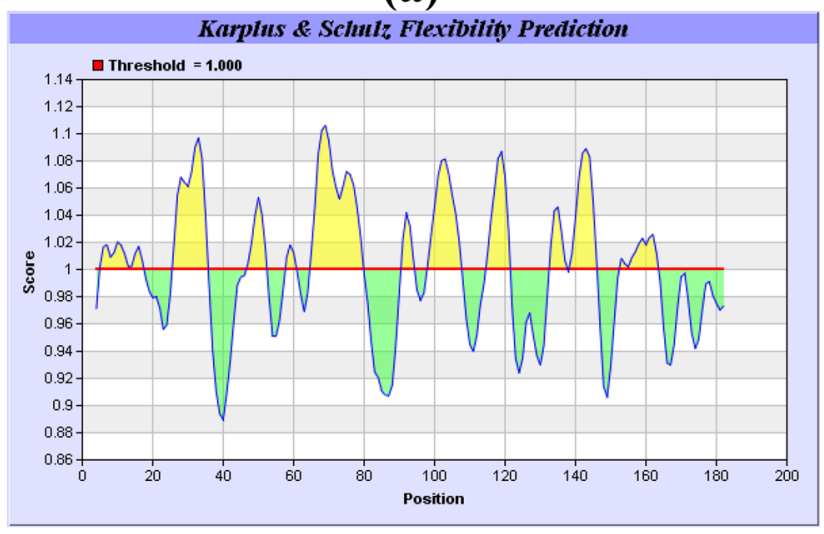

(c)

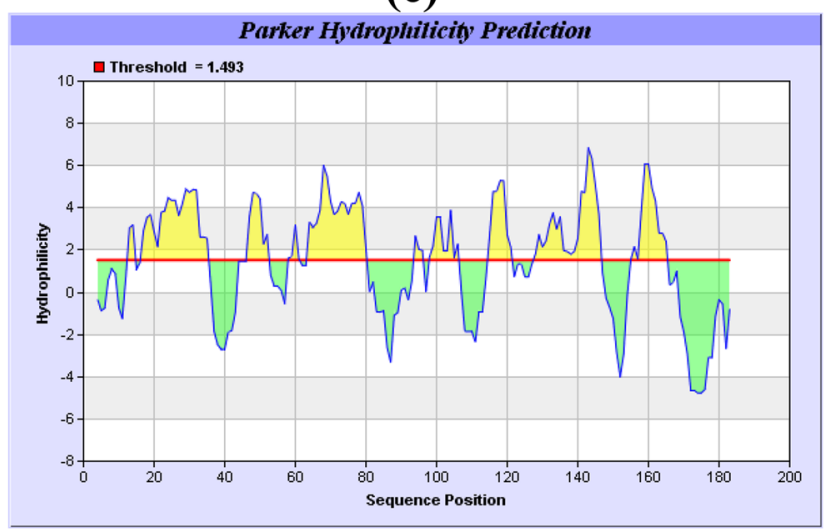

(e)

Fig. 1 a Chou and Fasman beta turn prediction for antigen no. 6. b Emini surface accessibility prediction for antigen no. 6. $\mathbf{c}$ Karplus and Schultz flexibility prediction for antigen no. 6. d Kolaskar and Ton-

(Uniprot ID:Q0PC24). It has been shown a total of 56 putative CTL epitopes, including 28 HLA-A (5-A1, 7-A2, 8-A3, 3-A24, 5-A26), and 28 HLA-B (1-B7, 9-B8, 5-B27, 2-B39, 2-B44, 4-B58, 5-B62), while the control Omp18 showed

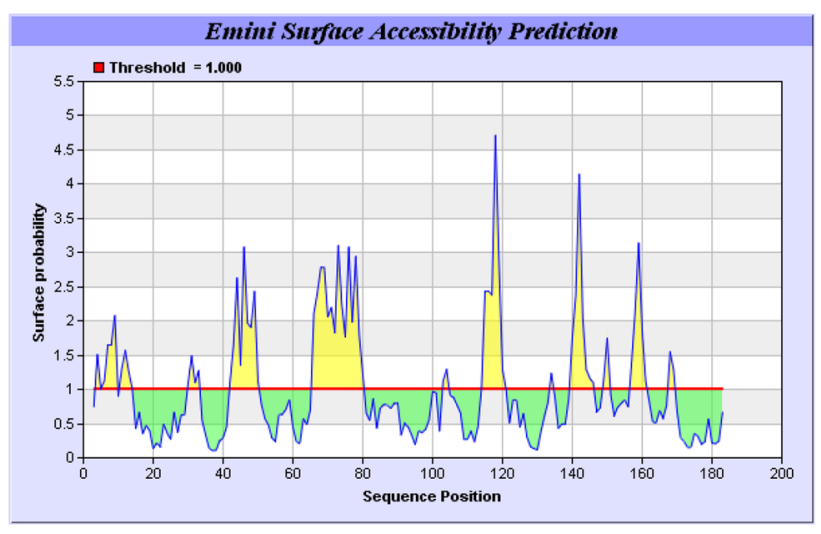

(b)

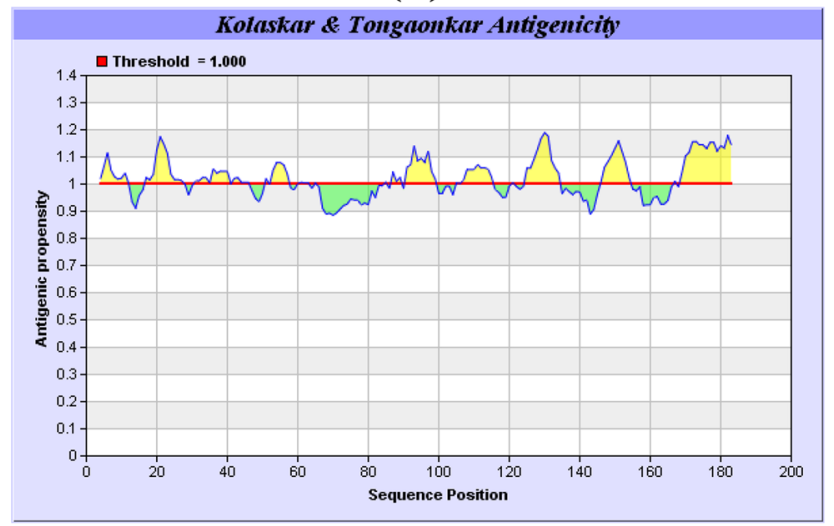

(d)

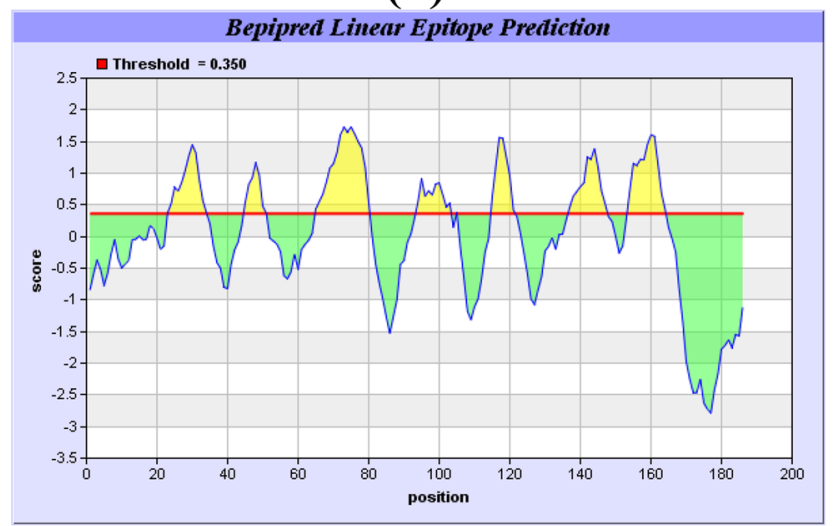

(f)

gaonkar antigenicity prediction for antigen no. 6. e Parker hydrophilicity prediction for antigen no. 6. $\mathbf{f}$ Bepipred linear epitope prediction for antigen no. 6

a total of 33 putative CTL epitopes, including 15 HLA-A (3-A1, 4-A2, 5-A3, 3-A24, 0-A26), and 18 HLA-B (1-B7, 5-B8, 2-B27, 1-B39, 2-B44, 3-B58, 4-B62) as shown below from Table $\mathrm{S} 4 \mathrm{a}, \mathrm{b}$, which is significantly lower than 
antigen no. 6. For HLA class II supertypes, a total of 371 putative HTL epitopes have been predicted using NetMHC II algorithm (Table S5a, b). The control antigen Q0PC24 has shown nine allelic epitopes. Overall, test antigen no. 6 has been found to show the highest number of supertype epitopes and thus has been predicted as best antigen.

\subsubsection{Selection of Optimal Epitope Sets Based on Population Coverage Analysis}

Epitope vaccines trigger an immune response by confronting the immune system with immunogenic peptides. Binding of these peptides to proteins from the major histocompatibility complex (MHC) is crucial for immune system activation. However, since the MHC is highly polymorphic, crucial step in design of a peptide vaccine is the selection of the set of epitopes which yields the best immune response in a given population or individual. Hence, key criteria for selection are, e.g., overall immunogenicity, tolerance for antigen mutations, population coverage, and antigen coverage. It has been demonstrated that a correlation exists between immunogenicity and MHC class I binding affinity [32]. It is, therefore, reasonable to use MHC class I binding affinity prediction methods for the prediction of immunogenicity. Table 3 shows results of population coverage analysis for target populations of campylobacteriosis. The epitope AMLTYMQWL from antigen no. 6 binds to allele A*0201 which have the highest frequency $(27.14 \%)$ in the population of Europe, the second highest frequency (14.48\%) in the population of North America, and the highest frequency (15.8\%) in the population of Southwest Asia.

\subsubsection{TCR-pMHC Interaction Analysis}

Antigen presentation and recognition occurs in two steps. The peptide ligand first binds to the major histocompatibility complex (MHC) molecule, then recognition of this peptide-MHC
(pMHC) complex by the T-cell receptor (TCR). Thus, adaptive immune response is triggered by specific T-cell receptors (TCR) binding to pMHC complexes. Here, the CTL epitope set predicted by NetCTL and optimized by Optitope for the different target populations has been used as the query peptide set and TCR-pMHC interactions have been analyzed. In TCR-pMHC interactions, the same hit peptide antigens have been obtained for all the three target populations. The epitope AMLTYMQWL has been found to have a joint $Z$ value of 4.87 , indicating that this peptide exhibits highly significant TCR-pMHC interactions (Fig. 2).

This hit peptide is homologous to template peptide GILGFVFTL, which is an epitope of matrix protein 1 of Influenza A virus as recorded in IEDB (Table 4). Hit peptide antigen has been obtained for antigen no. 6 Q0PA22, and in addition, it gave the best hit peptide for all the three populations; thus, it has high probability of exhibiting good pMHC-TCR interactions. Hence, it has been inferred as the most potential antigen.

\subsubsection{Epitope Homolog Mapping}

Using the 3D structural homology mapping tool, it becomes possible to determine the peptide sequence in a folded protein that would most closely depict the structure of a short peptide in solution. The top hit peptide AMLTYMQWL is homologous to template peptide GILGFVFTL as obtained by TCR-pMHC interaction analysis in the previous step. The peptide family of the template obtained contains 43 homologous peptide antigens from 27 organisms. Amongst these 43 homologous peptide antigens, the best homologous peptide GMLGFVFTL gave 3 PDB hits, and hence, it has been mapped to 3D structures of proteins available at PDB, using the homology mapping tool.

This best homologous peptide GMLGFVFTL exhibits the greatest homology with the peptide 58GILGFVFTL66

Table 3 The population coverage analysis of optimized CTL epitopes for different target populations

\begin{tabular}{|c|c|c|c|c|c|}
\hline Target population & $\begin{array}{l}\text { Covered } \\
\text { alleles/target alleles }\end{array}$ & $\begin{array}{l}\text { Population } \\
\text { coverage (\%) }\end{array}$ & Epitope & $\begin{array}{l}\text { Fraction of overall } \\
\text { immunogenicity }\end{array}$ & Covered alleles \\
\hline \multirow[t]{2}{*}{ Europe } & \multirow[t]{2}{*}{$18 / 19$} & \multirow[t]{2}{*}{99.6} & VLLFVFFAV & 0.12 & A*0201 \\
\hline & & & AMLTYMQWL & 0.07 & A*0201 \\
\hline \multirow[t]{2}{*}{ North America } & \multirow[t]{2}{*}{$16 / 16$} & \multirow[t]{2}{*}{99.23} & VYYKKSSSL & 0.12 & $\mathrm{~A} * 2402 \mathrm{Cw} * 0401$ \\
\hline & & & AMLTYMQWL & 0.04 & $\mathrm{~A}^{*} 0201$ \\
\hline \multirow[t]{2}{*}{ South-west Asia } & \multirow[t]{2}{*}{$18 / 19$} & \multirow[t]{2}{*}{96.23} & VLLFVFFAV & 0.12 & $\mathrm{~A} * 0201 \mathrm{~A} * 0205$ \\
\hline & & & AMLTYMQWL & 0.07 & $\mathrm{~A} * 0201 \mathrm{~A} * 0205$ \\
\hline \multicolumn{6}{|c|}{ Control antigen Q0PC24 } \\
\hline Europe & $9 / 19$ & 81.99 & & & \\
\hline North America & $7 / 16$ & 75.86 & & & \\
\hline South-west Asia & $4 / 8$ & 65.97 & & & \\
\hline
\end{tabular}




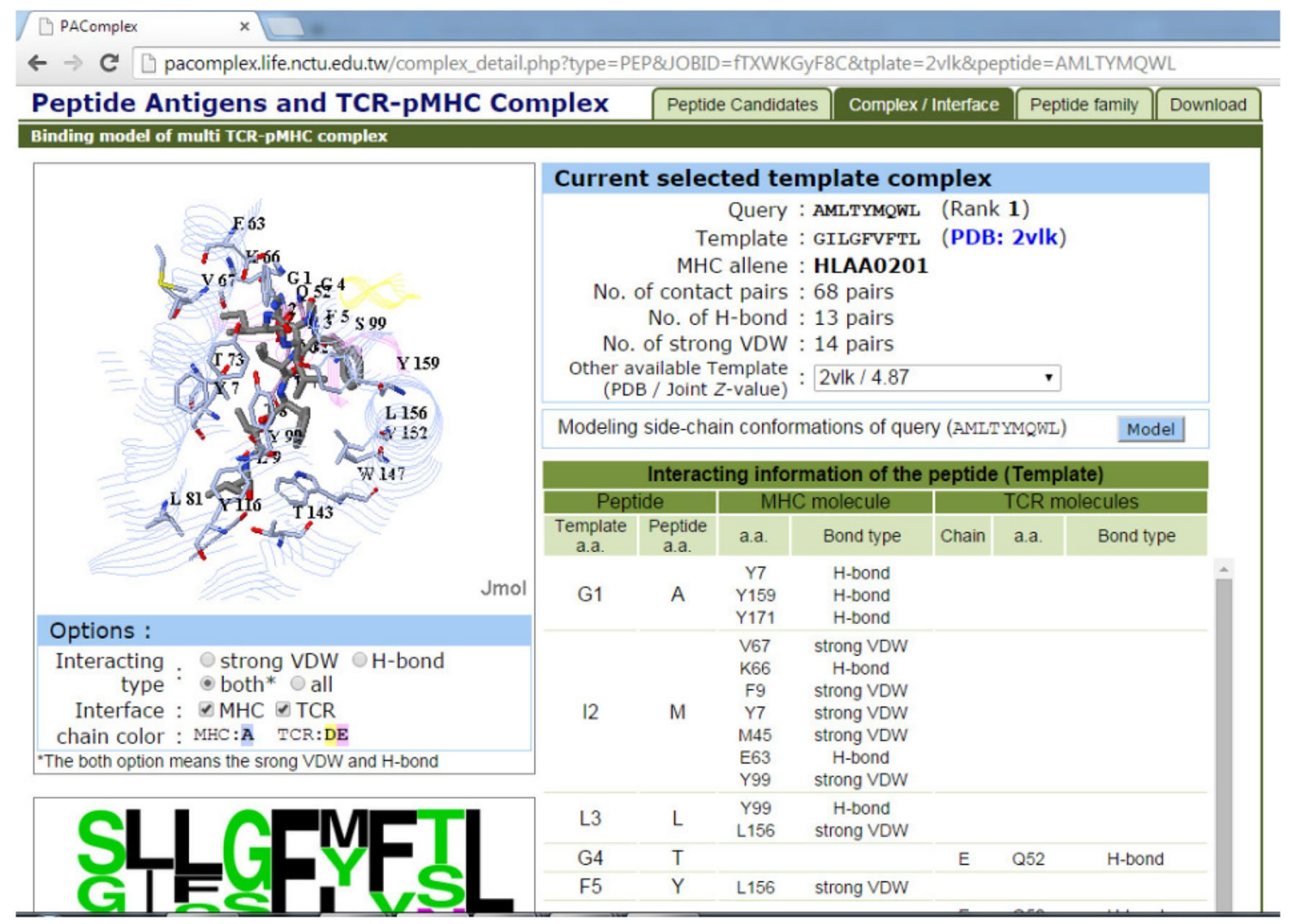

Fig. 2 PAComplex server showing pMHC-TCR interactions for the template peptide (GILGFVFTL)

(labeled in Fig. 3) from matrix protein 1 of influenza A virus ACROWKYOTOT12004 (H5N1) (chain A) (PDB ID: $2 z 16)$. It shared $99 \%$ sequence identity, with E value $5.63 \mathrm{E}-$ 85 . It has also been found to share eight out of nine identical residues with the peptide 58GILGFVFTL66. The residues 58-66 adopt a helix conformation, as evident from Fig. 3.

The homology mapping studies of the predicted epitope have been shown the best homology to the matched primary

Table 4 List of the top 5 hit CTL peptides for the three target populations, with their corresponding joint $Z$ value and homologous template peptide

\begin{tabular}{lllllll}
\hline Population & Rank & Peptide sequence & Joint $Z$ value & Best template & Template peptide & No. of identical residues \\
\hline Europe & 1 & AMLTYMQWL & 4.87 & $2 \mathrm{vlk}$ & GILGFVFTL & $2 / 9$ \\
& 2 & RMAELTTYL & 3.4 & $3 \mathrm{~d} 3 \mathrm{v}$ & LLFGFPVYV & $1 / 9$ \\
& 3 & VLLFVFFAV & 3.16 & $2 \mathrm{j} 8 \mathrm{u}$ & ALWGFFPVL & $2 / 9$ \\
& 4 & YMQWLSQGV & 1.63 & $2 \mathrm{p} 5 \mathrm{w}$ & SLLMWITQC & $0 / 9$ \\
North America & 1 & AMGDNIFAA & 1.58 & $1 \mathrm{qrn}$ & LLFGYAVYV & $0 / 9$ \\
& 2 & AMLTYMQWL & 4.87 & $2 \mathrm{vlk}$ & GILGFVFTL & $2 / 9$ \\
& 3 & RMAELTTYL & 3.4 & $3 \mathrm{~d} 3 \mathrm{v}$ & LLFGFPVYV & $1 / 9$ \\
South-west Asia & 1 & VLLFVFFAV & 3.16 & $2 \mathrm{j} 8 \mathrm{u}$ & ALWGFFPVL & $2 / 9$ \\
& 2 & YMQWLSQGV & 1.63 & $2 \mathrm{p} 5 \mathrm{w}$ & SLLMWITQC & $0 / 9$ \\
& 5 & AMGDNIFAA & 1.58 & $1 \mathrm{qrn}$ & LLFGYAVYV & $0 / 9$ \\
& 3 & AMLTYMQWL & 4.87 & $2 \mathrm{vlk}$ & GILGFVFTL & $2 / 9$ \\
& 4 & RMAELTTYL & 3.4 & $3 \mathrm{~d} 3 \mathrm{v}$ & LLFGFPVYV & $1 / 9$ \\
& 5 & VLLFVFFAV & 3.16 & $2 \mathrm{j} 8 \mathrm{u}$ & ALWGFFPVL & $2 / 9$ \\
& YMQWLSQGV & 1.63 & $2 \mathrm{p} 5 \mathrm{w}$ & SLLMWITQC & $0 / 9$ \\
\end{tabular}




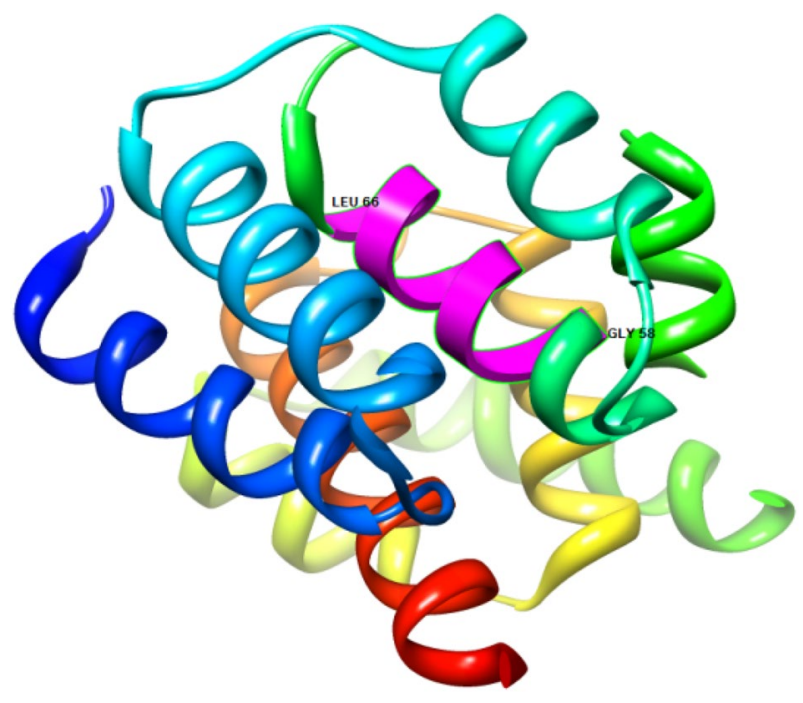

Fig. 3 3D image of the matrix protein 1 of influenza A virus showing the homologous peptide 58GILGFVFTL66, in magenta

sequence of matrix protein 1 of influenza A virus ACROWKYOTOT12004 (H5N1) (chain A), which is a well-known antigen inducing potential immune responses in the human host. Thus, 3D homology mapping increases the likelihood that a T-cell receptor raised against the peptide would be able to recognize, or cross-react with the corresponding epitope in the folded protein.

Keeping in mind the above observations, it can be deduced that the epitope AMLTYMQWL from antigen no. 6 (Q0PA22) has emerged as a promising vaccine candidate in this prediction strategy, and it can be considered to be capable of eliciting significant immune responses in experimental study so it should undergo further in vivo/in vitro investigations.

\section{Conclusion}

Vaccines elicit immune responses, provide protection against microorganisms, and are considered as one of the most successful medical interventions against infectious diseases. The development of an effective and affordable vaccine against campylobacteriosis is crucial for global public health. With the help of available and emerging epitope mapping tools, it is now possible to screen a whole proteome in silico, followed by advanced focus on the resulting sets of peptides. The prediction and analysis of HLA-binding sequences within protein antigens are fundamental to modern vaccine development. Nowadays, reverse vaccinology is being applied to many bacterial, viral, and eukaryotic pathogens and has shown to be of immense importance in all cases in providing novel antigens for the design of new vaccines. The present study involving approach of T-cell epitope prediction and their validation in vivo/in vitro is a very powerful strategy for rational antigen identification with the additional experimental work required to validate the epitope. This study involving extensive mining of the C. jejuni proteome for the identification of potential vaccine candidates can inspire similar strategies to be adopted for other species or pathogens for control of such serious disease. In recent times, the combined use of reverse vaccinology and immunoinformatics has emerged as the most promising approach in designing successful vaccine against infectious diseases as elucidated by these results. Further use of computational modeling and simulation shall predict the immunomodulatory effects of such vaccine candidates and thus offer an even better criterion for further in vitro or in vivo experimentation.

Acknowledgements The first author sincerely thanks the Institute of Engineering and Technology for providing necessary infrastructure and support for the work.

\section{Compliance with Ethical Standards}

Conflict of Interest Authors declare that they have no conflict of interest.

\section{References}

1. Van Vliet AH, Ketley JM (2001) Pathogenesis of enteric Campylobacter infection. Symp Ser Soc Appl Microbiol 30:45S-56S. doi:10.1046/j.1365-2672.2001.01353.x

2. Asakura M, Samosornsuk W, Taguchi M, Kobayashi K, Misawa N, Kusumoto M, Nishimura K, Matsuhisa A, Yamasaki S (2007) Comparative analysis of cytolethal distending toxin (cdt) genes among Campylobacter jejuni, $C$. coli and C. fetus strains. Microb Pathog 42:174-183. doi:10.1016/j.micpath.2007.01.005

3. Dasti JI, Tareen AM, Lugert R, Zautner AE, Gross U (2010) Campylobacter jejuni: a brief overview on pathogenicity-associated factors and disease- mediating mechanisms. Int J Med Microbiol 300:205-211. doi:10.1016/j.ijmm.2009.07.002

4. Adedayo O, Kirkpatrick BD (2008) Campylobacter jejuni Infections: update on presentation, diagnosis, and management. Hosp Phys 44:9-15

5. Gould SR (1985) Toxic megacolon complicating Campylobacter colitis. Br Med J (Clin Res Ed) 291:1580. doi:10.1136/ bmj.291.6508.1580-e

6. Butzler JP (1982) Campylobacter Enteritis. Infection 10:S67-69. doi:10.1007/BF01640857

7. Friedman CR, Neimann J, Wegener HC, Tauxe RV (2000) Epidemiology of Campylobacter jejuni infections in the United States and other industrialized Nations. In: Nachamkin I, Blaser MJ (eds) Campylobacter, 2nd edn. ASM International, Washington, pp 121-138

8. Gillespie IA, O'Brien SJ, Penman C, Tompkins D, Cowden J, Humphrey TJ (2008) Demographic determinants for Campylobacter infection in England and Wales: implications for future epidemiological studies. Epidemiol Infect 136:1717-1725. doi:10.1017/S0950268808000319 
9. https://www.cdc.gov/foodsafety/diseases/campylobacter/index. html. Accessed 28 May 2017

10. Havelaar AH, Van Pelt W, Ang CW, Wagenaar JA, Van Putten JPM, Gross U, Newell DG (2009) Immunity to Campylobacter: its role in risk assessment and epidemiology. Crit Rev Microbiol 35:1-22. doi:10.1080/10408410802636017

11. Lin J (2009) Novel approaches for Campylobacter control in poultry. Foodborne Pathog Dis 6:755-765. doi:10.1089/fpd.2008.0247

12. Albert MJ (2014) Vaccines against Campylobacter jejuni. Austin J Clin Immunol 1:3

13. Rappuoli R (2000) Reverse vaccinology. Curr Opin Microbial $3: 445-450$

14. Pizza M, Scarlato V, Masignani V et al (2000) Identification of vaccine candidates against serogroup B meningococcus by whole genome sequencing. Science 287:1816-1820. doi:10.1126/ science.287.5459.1816

15. Gorringe AR, Pajon R (2012) Bexsero: a multicomponent vaccine for prevention of meningococcal disease. Hum Vaccin Immunother 8:174-183. doi:10.4161/hv. 18500

16. Bagnoli F, Baudner B, Mishra RP, Bartolini E, Fiaschi L, Mariotti P, Nardi-Dei V, Boucher P, Rappuoli R (2011) Designing the next generation of vaccines for global public health. OMICS 15:545-566. doi:10.1089/omi.2010.0127

17. Moriel DG, Scarselli M, Serino L, Mora M, Rappuoli R, Masignani V (2009) Genome-based vaccine development: a short cut for the future. Adv Exp Med Biol 655:81-89. doi:10.1007/978-1-4419-1132-2_8

18. Burnens A, Stucki U, Nicolet J, Frey J (1995) Identification and characterization of an immunogenic outer membrane protein of Campylobacter jejuni. J Clin Microbiol 33:2826-2832

19. Petersen TN, Brunak S, Von Heijne G, Nielsen H (2011) SignalP 4.0: discriminating signal peptides from transmembrane regions. Nat Methods 8:785-786. doi:10.1038/nmeth.1701

20. Bendtsen JD, Kiemer L, Fausbøll A, Brunak S (2005) Nonclassical protein secretion in bacteria. BMC Microbiol 5:58. doi:10.1186/1471-2180-5-58

21. Doytchinova IA, Flower DR (2007) VaxiJen : a server for prediction of protective antigens, tumour antigens and subunit vaccines. BMC Bioinformatics 8:4. doi:10.1186/1471-2105-8-4

22. Magnan CN, Zeller M, Kayala MA, Vigil A, Randall A, Felgner PL, Baldi P (2010) High-throughput prediction of protein antigenicity using protein microarray data. Bioinformatics 26:2936-2943. doi:10.1093/bioinformatics/btq551

23. Hirose S, Noguchi T (2013) ESPRESSO: a system for estimating protein expression. Proteomics 13:1444-1456. doi:10.1002/ pmic. 201200175

24. Krogh A, Larsson È, Heijne GV, Sonnhammer ELL (2001) Predicting transmembrane protein topology with a hidden markov model: application to complete genomes. J Mol Boil 305:567580. doi:10.1006/jmbi.2000.4315

25. Moreno-hagelsieb G, Latimer K (2008) Choosing BLAST options for better detection of orthologs as reciprocal best hits. Bioinformatics 24:319-324. doi:10.1093/bioinformatics/btm585

26. Larsen MV, Lundegaard C, Lamberth K, Buus S, Lund O, Nielsen M (2007) Large-scale validation of methods for cytotoxic T-lymphocyte epitope prediction. BMC Bioinform 8:424. doi:10.1186/1471-2105-8-424

27. Nielsen M, Lund O, NN-align (2009) An artificial neural networkbased alignment algorithm for MHC class II peptide binding prediction. BMC Bioinform 10:296. doi:10.1186/1471-2105-10-296

28. Toussaint NC, Kohlbacher O (2009) OptiTope-a web server for the selection of an optimal set of peptides for epitope-based vaccines. Nucleic Acids Res 37:1-6. doi:10.1093/nar/gkp293

29. Liu I, Lo Y, Yang J (2011) PAComplex: a web server to infer peptide antigen families and binding models from TCR - pMHC complexes. Nucleic Acids Res 39:254-260. doi:10.1093/nar/ gkr434

30. Marrack P, Scott-Browne JP, Dai S, Gapin L, Kappler JW (2008) Evolutionarily conserved amino acids that control TCR-MHC interaction. Annu Rev Immunol 26:171-203. doi:10.1146/ annurev.immunol.26.021607.090421

31. Beaver JE, Bourne PE, Ponomarenko JV (2007) EpitopeViewer: a Java application for the visualization and analysis of immune epitopes in the Immune Epitope Database and Analysis Resource (IEDB). Immun Res. 3:1-6. doi:10.1186/1745-7580-3-3

32. Sette A, Vitiello A, Reherman B, Fowler P, Nayersina R, Kast WM, Melief CJ, Oseroff C, Yuan L, Ruppert J (1994) The relationship between class I binding affinity and immunogenicity of potential cytotoxic T cell epitopes. J Immunol. 153:5586-5592. doi:10.1186/1471-2105-15-241 